\title{
The changing pattern of spinal arachnoiditis
}

\author{
M. D. M. S H A W, J . A . R US S E L , A N D K. W . G R O S S A T \\ From the Institute of Neurological Sciences, Southern General Hospital, Glasgow
}

SUMMARY Spinal arachnoiditis is a rare condition. Eighty cases, diagnosed during a period when 7600 spinal contrast investigations were undertaken, have been reviewed. The majority had suffered a previous spinal condition, the most common being lumbar disc disease. There has been a change in the distribution of arachnoiditis with the lumbar region now most frequently involved. This accounts for the persistence of radicular symptoms and the relatively low incidence of paraplegia when compared with earlier series. Surgery does not appear to have any role in the treatment.

It was not until Horsley's (1909) description under the title "chronic spinal meningitis" that spinal arachnoiditis became the first type of arachnoiditis to be recognised as a separate disease entity, although both Spiller et al. (1903) and Mendel and Adler in 1908 (quoted by Elkington, 1936) reported localised cystic lesions deep to the pia mater, and Schwarz (1897) had described it during his description of syphilitic meningomyelitis associated with cavitation of the cord. Since then the condition has been described as "adhesive spinal arachnoiditis" (Stookey, 1927), "meningitis serosa circumscripta spinalis" (Elkington, 1936), and "spinal adhesive arachnoiditis" (Mackay, 1939).

Elkington (1951) stated that the natural history is for the condition to progress to paraplegia, but he and other authors (Kulowski and Scott, 1934; Elsberg, 1942; Rocovich, 1947) agreed that surgical decompression is the only, if limited, prospect of relief, or of achieving a static state. However, French (1946) and Lombardi et al. (1962) felt that this was not justifiable as at best the patients gained only a very transient degree of relief.

In view of the changing patterns in this condition and the continuing dichotomy as to whether direct surgery has any place in the treatment (Ransford and Harries, 1972), we felt that it would be worthwhile reviewing the experience gained in the Institute of Neurological Sciences, Glasgow, over the past 21 years. Statistical significance was determined by using the chi-square test. Values of 0.05 were accepted as being significant.

Address for reprint requests: Mr J. A. Russell, Division of Neurosurgery, Institute of Neurological Sciences, Southern General Hospit:i, - Glasgow G5I 4TF. Scotland.

Accepted 21 July 1977

\section{Case material}

INCIDENCE

During the period January 1955 to September 1976 spinal arachnoiditis was diagnosed in 80 patients, 18 of whom presented in the first 10 year period. The male:female ratio was $2: 1$. The histogram (Fig. 1) shows the sex distribution according to age in decades, the range being 8 to 73 years.

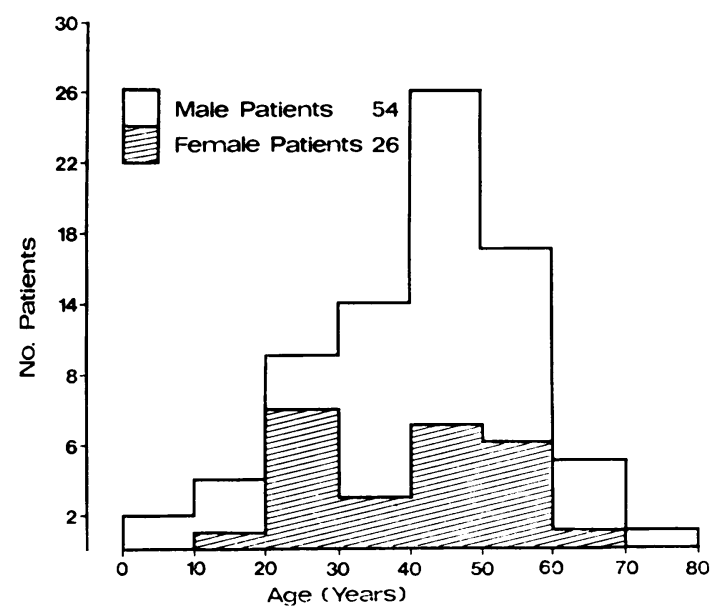

Fig. 1 Spinal arachnoiditis: age and sex distribution.

SITES

The lumbosacral region was the sole site affected in $71 \%$ of the cases. In a further $20 \%$ the thoracic region was also involved, and the whole spinal canal in $5 \%$. In only $4 \%$ was the thoracic region alone affected, and there were no cases in 
whom the condition was restricted to the cervical region.

\section{DIAGNOSTIC METHODS}

All but one of the patients underwent positive contrast myelography (meglumine iothalamate $60 \% \mathrm{w} / \mathrm{v}$ (Conray 280: May and Baker) in 15 patients, and iophendylate (Myodil: Glaxo) in 64) at the time of diagnosis of the arachnoiditis. The remaining patient was diagnosed post mortem (the cause of death was found to be an occlusion of the left common carotid artery) some 17 years

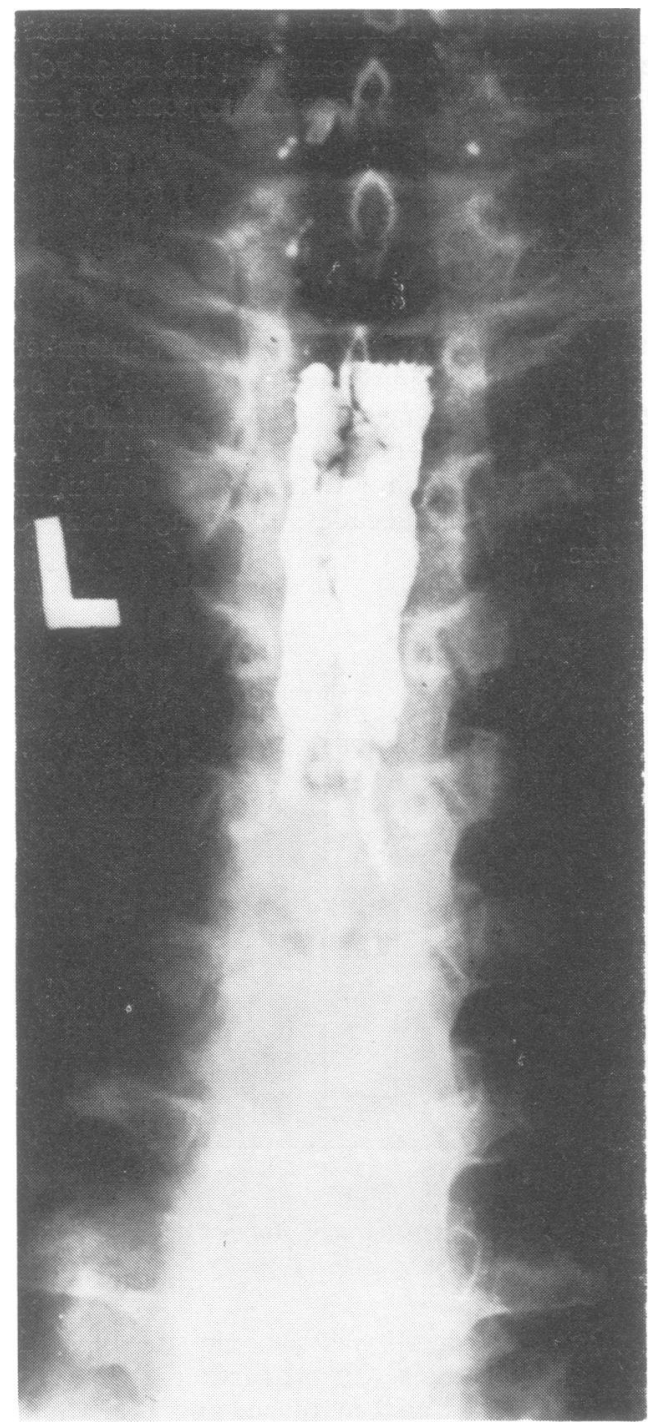

Fig. 2 Myelogram showing block at upper border of first thoracic vertebra. after the onset of symptoms attributable to spinal arachnoiditis. The myelographic criteria used to make the diagnosis were:

1. Partial or complete block (Fig. 2).

2. Narrowing of the subarachnoid space (Fig. 3).

3. Obliteration of the nerve root sleeves and thickening of the nerve roots (Figs. 3 and 4).

4. Irregular distribution and loculation of the contrast medium (Fig. 4).

5. Fixity of previously inserted contrast medium (Fig. 5).

6. Pseudo-cyst formation.

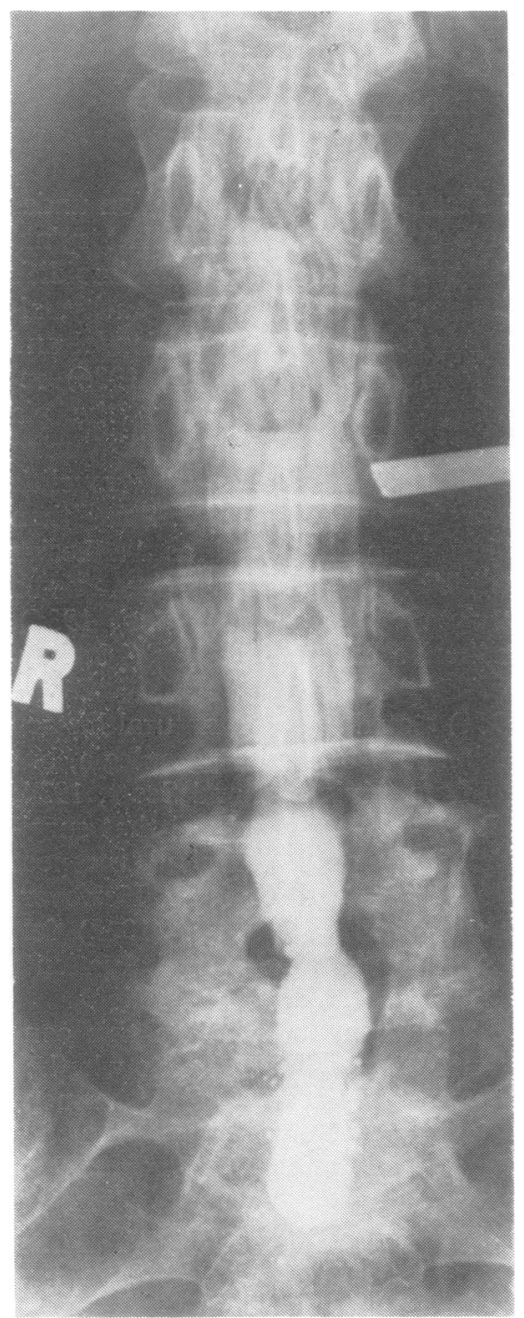

Fig. 3 Water-soluble myelogram showing narrowing of subarachnoid space, adherence of nerve roots to arachnoid mater, and obliteration of nerve root sleeves. 


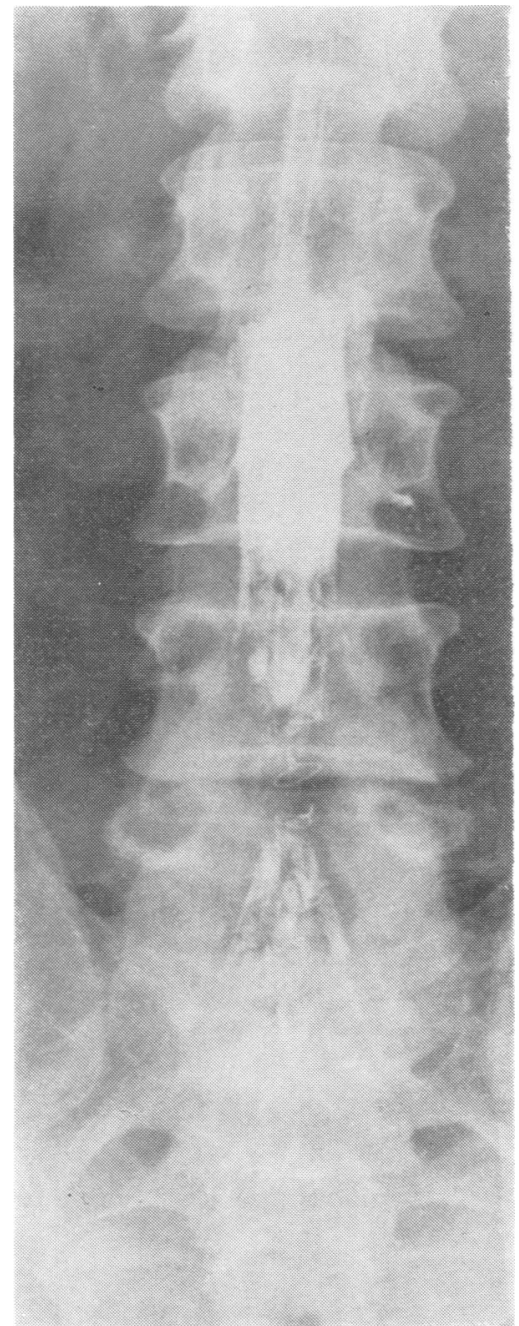

Fig. 4 Water-soluble myelogram showing irregular distribution of contrast medium and thickened nerve roots.

At the time of the study the myelograms of 77 patients were reviewed. Two patients' films had been mislaid but each had been diagnosed as spinal arachnoiditis at the time of the original reporting of the myelogram. Of the 77 patients, two of the above myelographic features were found in all the patients except one in whom the diagnosis was radiologically uncertain. The frequency with which the radiographic criteria was found is shown in Table 1.

Thirty-one of the patients (including the one in whom, on review of the radiology, the diagnosis was felt to be uncertain, and one of those whose

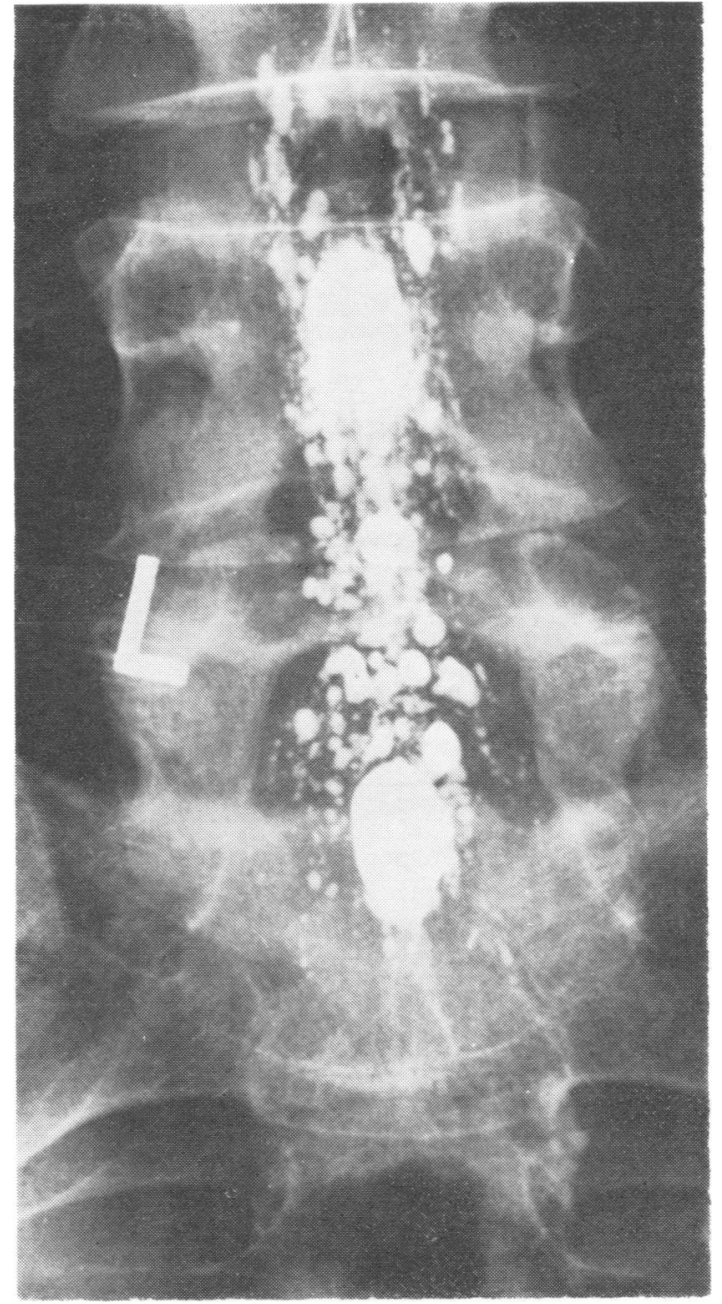

Fig. 5 Plain radiograph showing fixity of previously inserted contrast medium.

films were lost) were submitted to surgery which allowed confirmation of the diagnosis.

PREVIOUS SPINAL CONDITIONS

Ninety-four per cent of the patients had undergone a previous illness or treatment involving the spinal column or its contents. The most common condition was intervertebral disc disease which had been diagnosed in $64 \%$ of all the patients, and of these, all but one suffered from lumbar disc disease. Of the latter, $10 \%$ also developed a second spinal disease (Table 2). Primary infections, which had all required multiple lumbar punctures for the administration of intrathecal antibiotics had been diagnosed in $15 \%$ of the 
Table 1 Spinal arachnoiditis-radiographic findings

\begin{tabular}{|c|c|c|c|}
\hline \multirow[b]{2}{*}{ Radiographic findings } & \multirow[b]{2}{*}{ No. } & \multicolumn{2}{|c|}{$\begin{array}{l}\text { Arachnoiditis treatment } \\
\text { groups }\end{array}$} \\
\hline & & Operation & No operation \\
\hline Block & 41 & 21 & 20 \\
\hline Globulation & 59 & 25 & 34 \\
\hline Nerve thickening & 25 & 9 & 16 \\
\hline Fixed contrast & 56 & 20 & 36 \\
\hline Narrow subarachnoid space & 65 & 23 & 42 \\
\hline No radiographs & 1 & - & 1 \\
\hline Lost radiographs & 2 & 1 & 1 \\
\hline Uncertain diagnosis & 1 & 1 & 0 \\
\hline Total number of patients & 80 & 31 & 49 \\
\hline
\end{tabular}

Table 2 Spinal arachnoiditis-diseases occurring together with lumbar disc disease

\begin{tabular}{ll}
\hline Second disease & Number of patients \\
\hline Injury & 2 \\
Postoperative infection & 1 \\
Spinal angioma & 1 \\
Multiple sclerosis & 1 \\
Total & 5 \\
\hline
\end{tabular}

patients. Seventy-five per cent of these infections were tuberculous and the remainder pyogenic. Injury accounted for a further $9 \%$ of the patients, while tumours $(3 \%)$, subarachnoid haemorrhage $(1 \%)$, spinal anaesthetic $(1 \%)$, and previous cordotomy $(1 \%)$ were all uncommon.

Sixty-four patients had undergone a previous lumbar puncture either for diagnostic or therapeutic reasons. Twelve of these patients had no record of whether blood was present in the cerebrospinal fluid either macroscopically or microscopically. In the remaining 52 patients, blood was present in $8 \%(75 \%$ of which was only detected on microscopy).

During the course of investigation of their initial complaint 43 patients had been submitted to myelography, but in only one case was a watersoluble con'rast medium used. The myelograms were examined for evidence of technical difficulties, and $39 \%$ showed such evidence. Only two of these 17 myelograms had evidence suggesting leakage of cerebrospinal fluid alone; the remainder showed subdural or extradural extravasation of contrast medium. In order to compare this incidence with that occurring during a series of myelograms, 50 consecutive myelograms undertaken at the Institute were reviewed. In this series, leakage of the dye outside the subdural space was found in $6 \%$. In a further $2 \%$ leakage occurred and resulted in concentric constriction in the lumbar sac at the level of the spinal puncture.
Of the 36 patients with arachnoiditis who underwent myelography during assessment of their lumbar disc disease, 24 were demonstrated to have a lesion at one level, eight at multiple levels, and four were negative. Only one of these patients was investigated using meglumine iothalamate $60 \% \mathrm{w} / \mathrm{v}$.

Fifty-one patients had previously undergone spinal surgery: two for tumours (both dermoid tumours in the lumbar canal), one for spinal subarachnoid haemorrhage in whom the only finding was of a swollen cervical cord, and one for an anterolateral cordotomy undertaken for pain after a traumatic amputation of the right arm. Forty-seven patients underwent surgery for lumbar disc disease: $77 \%$ were submitted to a fenestration procedure, $11 \%$ to a laminectomy ( $60 \%$ of which were hemilaminectomies), and in the remainder the approach was unknown. Multiple level exploration was undertaken in $62 \%$ of the 47 patients $(79 \%$ of which were at two levels, $14 \%$ at more than two levels and in the others, though multiple, the actual number is unknown) and $26 \%$ were bilateral explorations. In order to compare this incidence with that occurring in a general population undergoing lumbar disc surgery, the cases operated upon during six years selected at random from the period under study, were analysed. Exploration at more than one level was carried out in $50 \%$ of these patients, and 3\% were explored bilaterally.

Of the seven patients who ultimately became paraplegic, two had sustained injuries, two had had tuberculous meningitis, two dermoid tumours, and one a prolapsed lumbar intervertebral disc removed.

\section{TIME INTERVAL}

The time intervals, between investigation and/or treatment of the initial spinal condition and the onset of symptoms which were attributable to the arachnoiditis varied from immediately to 27 years (Table 3). Symptoms developed within one

Table 3 Spinal arachnoiditis-time interval from primary disease to symptomatic onset

\begin{tabular}{lcc}
\hline Time interval & Number of patients & $\%$ total \\
\hline Less than 1 month & 16 & 20 \\
1-6 months & 13 & 16 \\
6-12 months & 10 & 13 \\
12-24 months & 8 & 10 \\
2-5 years & 13 & 16 \\
5-10 years & 3 & 4 \\
10-20 years & 9 & 11 \\
More than 20 years & 3 & 4 \\
No primary disease & 5 & 6 \\
Total & 80 & 100 \\
\hline
\end{tabular}


year in $49 \%$, but in $15 \%$ the interval was greater than 10 years.

\section{CLINICAL FEATURES}

In 21 patients root signs were either absent or unilateral, but most of these $(90 \%)$ complained of bilateral sciatica. Only five patients showed either no root signs or had signs limited to one root (Table 4). The remaining 59 patients had both bilateral symptoms and signs. Three patients were paraplegic and a further 11 paraparetic. The bladder of one of the latter was paralysed and in a second there was difficulty emptying completely. Among the other 66 patients only one had impaired bladder function. Straight leg raising was recorded in 68 patients at the time of diagnosis of arachnoiditis; 33 were abnormal and 35 normal.

Table 4 Spinal arachnoiditis-presence of clinical features

\begin{tabular}{lcc}
\hline Clinical features & $\begin{array}{l}\text { At time of } \\
\text { diagnosis }\end{array}$ & At outcome or death \\
\hline Paraplegia & 3 & 7 \\
Quadriparesis & 1 & 1 \\
Paraparesis & 11 & 10 \\
Multiple roots & 60 & 45 \\
Single root & 2 & 3 \\
Pain alone & 1 & 1 \\
$\quad$ Back alone & - & - \\
$\quad$ Sciatica & 2 & 3 \\
$\quad$ Unilateral & - & 4 \\
Bilateral & - & 6 \\
Pain free & 80 & 80 \\
Totollow-up & & \\
\hline
\end{tabular}

\section{TREATMENT}

Thirty-one patients were treated by decompressive laminectomy. In this group there were significantly more patients with a spinal block than in the non-surgical groups (Table 1) $\chi^{2}=5.5097 \mathrm{P}<0.02$ ). The dura mater was left open in eight instances, and a prolapsed intervertebral disc was removed from one case. Nerve root decompression was carried out in a further two patients as it was felt that, in addition to the arachnoiditis, compression by the superior facet was at least in part responsible for the symptoms. An arachnoidal cyst was decompressed in another case.

Only six patients were treated with courses of steroids and no patient with radiotherapy.

\section{OUTCOME}

The duration of follow-up achieved is shown in Table 5, and the final condition of the patients in Table 4. There were four deaths: after 17 years from carotid artery occlusion; after four years,
Table 5 Spinal arachnoiditis-follow-up

\begin{tabular}{ll}
\hline D:ration $(y r)$ & Number of patients \\
\hline 1 & 12 \\
$1-2$ & 14 \\
$2-5$ & 26 \\
$5-10$ & 12 \\
$10-20$ & 9 \\
20 & 1 \\
None & 6 \\
Total & 80 \\
\hline
\end{tabular}

cause unknown; after three years from a cardiac infarct; and after 14 months, sudden death under criminal circumstances. Only in the second patient was the arachnoiditis progressive: in the other three it remained static. Progression of the disease occurred in $25 \%$ of all the patients (Table 6), four further patients becoming paraplegic (Table 4). In addition to the seven paraplegic patients, incontinence of urine was present in three other patients, two who had difficulties at the time of diagnosis and the third with a spastic quadriparesis which progressed over four years. The progressive group also included one patient whose symptoms had been static for 13 years until, after a back injury, his pain became more severe. Fifty per cent of the patients remained in a static condition, and this includes the three patients who were already paraplegic at the time of diagnosis. All the patients who were paraparetic were able to walk, though two required walking sticks and one experienced claudication which was not due to peripheral vascular disease, on walking 200 yards. Of the four patients who were symptomless, two had undergone decompressive laminectomies and, in addition, in one case a prolapsed intervertebral disc which was thought to be contributing to the symptomatology was removed. The two conservatively managed patients had been free from symptoms for two and three years respectively, and those after surgery for one and two years.

Table 6 Spinal arachnoiditis-results of surgery and conservative treatment

\begin{tabular}{lccc}
\hline Symptoms & Total & Operation & No operation \\
\cline { 1 - 3 } No symptoms & 4 & 2 & 2 \\
Static & 3 & 3 & - \\
$\quad$ Paraplegia & 37 & 10 & 27 \\
$\quad$ Other symptoms & 20 & 9 & 11 \\
Progressive & 5 & 3 & 2 \\
Improved & 3 & 3 & - \\
$\quad$ Good & 6 & 1 & 5 \\
Moderate & 2 & - & 2 \\
Follow-up too short & 80 & 31 & 49 \\
Total & & & \\
\hline
\end{tabular}


In comparing surgical and non-surgical results (Table 6), marginally more patients were improved in the operation group than in the conservative group $\left(\chi^{2}=4.9123 \mathrm{P}<0.05\right)$. The improvement in the former group has been maintained for periods from six months to over four years, and in the latter for six months and two years. There was no other significant difference between the groups. The presence or absence of a spinal block did not influence the outcome, nor was there any relationship between the cerebrospinal fluid protein level (which varied from normal to $12 \mathrm{~g} / \mathrm{l}$ ) and the outcome: neither was there any relationship with the cerebrospinal fluid white cell counts which were normal except in two cases.

\section{Discussion}

Symptomatic spinal arachnoiditis is a relatively rare condition in which there is scar tissue within and between the leptomeninges. During the period under study 7600 spinal contrast investigations and 2900 explorations for lumbar disc disease have been carried out at the Institute. Arachnoiditis has been diagnosed more frequently in the second 10 year period than in the first. The number of positive contrast spinal investigations has risen from 250 per annum in 1961 to 678 in 1976. The latter consists of 330 iophendylate myelograms, 256 water soluble myelograms (virtually all using meglumine iothalamate $60 \% \mathrm{w} / \mathrm{v})$, and 92 reinvestigations.

The incidence (Fig. 1) of spinal arachnoiditis remains highest in the 30-50 year age group (Elkington, 1936; French, 1946; Lombardi et al., 1962; Lombardi and Passerini, 1964). No previous report was found in the English literature describing the condition in patients under 10 years of age: one of the present patients was 8 years old and a second, 9. Elkington (1936) reported a male : female ratio of $3: 1$, but Lombardi and Passerini (1964) like us, found it to be $2: 1$. Jacobsen and Lester's report (1969) was unusual in that the ratio was $6: 1$.

Spinal arachnoiditis may be localised or generalised. Though in 1951 Elkington wrote that there was still a slight preponderance of cases situated in the cervical region, he had previously found (1936) that $29 \%$ were restricted to the cervical, $59 \%$ to the thoracic (including the thoracolumbar junction), and $12 \%$ to the lumbosacral spine. This is in agreement with other reports (Horsley, 1909; Lombardi et al., 1962) in which the majority of cases were thoracic. French (1946) was the first to report the swing to a high incidence in the lumbar region $(46 \%)$. This trend has continued, $71 \%$ of our cases involving the lumbosacral region alone, and in only $4 \%$ was there no involvement of the lumbosacral region. The arachnoiditis was limited to one vertebral level in only $4 \%$ of all our patients.

Malmros (1976) analysed the incidence of arachnoiditis in all the patients reported by Autio et al. (1972), Ahlgren (1973), Radberg and Wennberg (1973), and Irstam and Rosencrantz (1973, 1974), who had undergone water-soluble myelography and subsequently returned for reinvestigation. The high incidence found $(49 \%)$ was probably due to the acceptance of blunting or amputation of the root sleeve alone as radiological evidence of arachnoiditis. We do not feel that this is sufficient evidence to make the diagnosis. Indeed of Autio et al.'s (1972) original six patients fitting this criterion, one has died of malignancy and on histological examination no evidence of arachnoiditis was found (Irstam and Rosencrantz, 1974; Malmros, 1976). We have, therefore, like other workers (Seaman et al., 1953; Lombardi and Passerini, 1964; Austin, 1972) only accepted the more rigid criteria described above. Based on the facts that 7600 myelograms have been undertaken, that in a study of lumbar disc disease Jennett and Shaw (1976) were able, in the area served by the Institute, to achieve a follow-up rate of $67 \%$, and that 43 of the patients in the present series had been submitted to previous myelography, the incidence of symptomatic spinal arachnoiditis after this procedure would seem to be approximately $1 \%$. We have no experience of the technique of air myelography used by Jacobsen and Lester (1969) for confirmation of the diagnosis, but it is important, before undertaking a second myelogram, to obtain plain radiographs of the spine (Fig. 5) which may show the characteristic fixation of residual contrast medium which is deposited in droplets and streaks (Christensen, 1942).

Various aetiological factors have been implicated in the development of spinal arachnoiditis. The relative importance of each has changed with the passage of time. Most of our patients had preexisting intraspinal disease.

Infection was the first condition to be associated with spinal arachnoiditis. Schwarz's (1897) case was secondary to syphilis, as were some of Horsley's (1909). The latter author attributed the remaining cases to the gonococcus on indirect and, therefore, inconclusive evidence. Since then many authors have described the condition after bacterial, including tuberculous, infections (Elkington, 1936; Rocovich, 1947; Lombardi et al., 1962). This was felt to be the most common cause, and has been 
compounded by the use of intrathecal therapyfor example, penicillin (Erickson et al., 1946; Millikan and Sahs, 1947), and sulphonamide drugs (Lombardi et al., 1962). Lymphocytic meningitis has also been described as a predisposing condition (Barker and Ford, 1937).

Blood in the cerebrospinal fluid produces an inflammatory reaction in the leptomeninges (Bagley, 1928a,b; Hammes, 1944; Alpers and Forster, 1945). Spinal arachnoiditis after subarachnoid haemorrhage though described (Lombardi et al., 1962) is uncommon $(1 \%$ in the present series). However, this may account for the relatively high incidence of spinal trauma, with or without a fracture (Elkington, 1936; Elsberg, 1942; Lombardi et al., 1962) in patients with arachnoiditis. Spinal anaesthetics were cited as the commonest aetiological factor by Winkelman et al. (1953) and Austin (1972). Rosenbleum et al. (1952) described six cases after 1272 spinal anaesthetics, while Kennedy et al. (1945) estimated the risk of grave neurological deficit after spinal anaesthesia to be $0.5 \%$, of which approximately half were due to spinal arachnoiditis (Kennedy et al., 1950). Particles of haemosiderin found in a biopsy specimen (Weiss et al., 1962) supported the suggestion made by Austin (1972) that faulty technique was the cause. However, Greenfield (quoted by Meyer, 1963) thought that chemical contamination was the causative factor. Kennedy et al. (1945) felt that pre-existing central nervous system disease was a contraindication to the use of spinal anaesthesia, because this combination led to an increased risk of serious neurological deficit. Chemical inflammation may be the mechanism of production of arachnoiditis in the two cases who had dermoid tumours removed in the present series, though the condition has been described after surgery for other types of benign intraspinal tumours (Davidoff et al., 1947).

Positive contrast myelography has been implicated in the aetiology of spinal arachnoiditis, and experimentally (Bergeron et al., 1971), at least using iophendylate, blood potentiates the effect. Howland and Curry (1966) demonstrated that intrathecal steroids introduced simultaneously with the blood and iophendylate greatly reduce the risk of developing a severe arachnoiditis. However, Bernat et al. (1976) implicated intrathecal "Depo Medrol" in the production of a severe stenotic meningeal reaction in patients with multiple sclerosis, which they thought might be due to the vehicle rather than to the steroid itself. Patients suffering from multiple sclerosis seem to be more reactive to intrathecal injections (Bernat, 1977) and, in particular, to iophendylate myelography
(Kaufmann and Jeans, 1976) than other patients. Whether the patients in our retrospective series were allergic individuals cannot be certain, but it would seem unlikely as only one of the 61 patients undergoing myelography developed a temperature after the myelogram (as compared with $6 \%$ of 60 random myelograms), and none developed any other allergic phenomena such as bronchospasm or skin rashes. A single patient was known to have a drug sensitivity, namely to PAS.

Removal of the iophendylate immediately upon completion of the investigation does not necessarily protect the patient from the risk of developing arachnoiditis (Peacher and Robertson, 1945). The water-soluble contrast media are not free from this complication (Autio et al., 1972; Ahlgren, 1973; Halaburt and Lester, 1973; Radberg and Wennberg, 1973; Irstam et al., 1974; Irstam and Rosencrantz, 1973, 1974; Liliequist and Lundström, 1974; Slätis et al., 1974; Malmros, 1976). Though various authors (Ahlgren, 1973; Halaburt and Lester, 1973; Irstam et al., 1974; Irstam and Rosencrantz, 1974) have claimed that the incidence varies between the different contrast media, Malmros's composite figures suggest little difference between methiodal (Kontrast $U$ ), methylglucamine iothalamate (Dimer-X), and meglumine iothalamate (Conray 60). An increasing amount of contrast medium, and hence concentration in the cerebrospinal fluid, results in an increased incidence of severe arachnoiditis (Halaburt and Lester, 1973). The resultant increase in osmolarity of the cerebrospinal fluid could be the precipitating factor (Slätis et al., 1974), but Halaburt and Lester (1973) also found that the risk was higher if the cerebrospinal fluid protein was above the normal range. In this series, of 61 patients who had a lumbar puncture at the time of the previous spinal complaint, only six had a cerebrospinal fluid protein content greater than $0.5 \mathrm{~g} / 1$, and only one of these underwent myelography: the other five patients had all suffered infections. The striking feature in the present series is the very high percentage $(39 \%)$ of myelograms which showed evidence of a technical difficulty, even though very few cases had bloody fluid even on microscopy. This is significantly greater than the incidence of $8 \%$ found in a consecutive series of 50 myelograms $\left(\chi^{2}=13.1507 \mathrm{P}<0.001\right)$. It would, therefore, seem important that the lumbar puncture, necessary for myelography, should be carried out by someone who has considerable and frequent experience of the procedure in order to reduce the chances of an extra- or subdural injection of contrast medium. If water-soluble myelography is followed by surgery, a much 
higher incidence of spinal arachnoiditis has been noted-for example, Liliequist and Lindström (1974) found $16 \%$ in the non-operation group as against $58 \%$ in an operation group, and Irstam and Rosencrantz (1974) found $24 \%$ in the nonoperation group and $69 \%$ in the operation group. These high incidences may be due to the less rigid criteria adopted for the diagnosis of the condition as compared with the present series. Furthermore, there were only three patients who had an uncomplicated myelogram, no surgery, and no previous spinal illness, suggesting that the incidence of spinal arachnoiditis in this situation is very low. Since 1971 water soluble myelograms have been in regular use in the Institute, constituting $44 \%$ of the new investigations. In view of this, together with the facts that only one of the patients in this series had been investigated using water-soluble contrast medium and that half the patients with the condition developed their symptoms within one year, it would seem that the risk of developing symptomatic spinal arachnoiditis is considerably less with water-soluble contrast medium, than after iophendylate.

That arachnoiditis might complicate lumbar disc disease was recognised by French (1946), Smolik and Nash (1951), and Ransford and Harries (1972). No particular feature leading to an increased incidence of this complication was identified. The number of intervertebral disc levels explored was not markedly different in our series as compared with the control group, but there were over eight times as many bilateral explorations in the patients with arachnoiditis. A possible explanation is that in unilateral explorations the dura mater is displaced in only one direction, but in bilateral explorations there is less space and circumferential leptomeningeal damage may be inflicted as a result of the retraction.

In a few cases (five in the present series), no preceding reason for the arachnoiditis was found and in particular no history of allergy was obtained. No single site was preferentially involved. Duke and Hashimoto (1974) described six cases in one family which they felt was genetically determined as an autosomal dominant factor, but in none of our cases was there a familial tendency.

Various factors are, therefore, involved in the production of spinal arachnoiditis. Not infrequently these are multiple-for example, two separate diseases affecting the spinal column or its contents, or a single condition with technical difficulties.

The time interval between the precipitating factor and the onset of symptoms arising from the arachnoiditis varies. Half developed symptoms in less than one year, but in $16 \%$ it was greater than 10 years. Patients usually complained of bilateral sciatica. Only one patient did not and he suffered back pain only, although his arachnoiditis involved the lumbar region. Most patients show objective evidence of multiple root lesions, but frequently it is the severe pain, which is not always strictly radicular, that is the predominant complaint.

The role of direct surgery in the treatment of spinal arachnoiditis remains in question. Elsberg (1942) obtained relief for $25 \%$ of his patients and a further $25 \%$ were improved. The improvement was related to a short history. Brain and Walton (1969) state that surgery improves some $30 \%$ and results from the relief of the cystic component of the arachnoiditis. Elkington (1951) agreed that if cystic changes were present surgery was of help, but in the majority of cases there was, as earlier writers had found, an inexorable progression which at the extreme would result in paraplegia due to intramedullary cavitation (Schwarz, 1897; Mackay, 1939; Lubin, 1940). Furthermore, surgery may result in more nerve root damage (French, 1946). In the present series there were marginally more patients in the operation group who were improved than in the non-operation group $(P<0.05)$, but this was not related to the duration of the symptomatology. However, it is important to exclude additional pathology as the cause of the pain, for example a prolapsed intervertebral disc or the superior facet syndrome, because there are some patients with proven asymptomatic arachnoiditis. There are four such patients in this series and Malmros (1976) has described a further two cases. There are insufficient cases in this series to decide whether leaving open the dura mater confers any added benefit.

Feder and Smith (1962) reported that radiotherapy resulted in an excellent clinical response in $23.5 \%$ of patients, a limited response in $23.5 \%$, and arrest of progression in $29 \% ; 23.5 \%$ continued to progress. Of the excellent responders $50 \%$ had also undergone surgery, and of those who responded in a limited way the majority (all except one) would have been considered as static in this present series. Thus the percentage of patients in the static and progressive groups do not differ from those in the present series. We, therefore, agree with French (1946) that radiotherapy is of no benefit.

Though steroids may have some protective value, if given at the time of the precipitating event (Howland and Curry, 1966), they are unlikely to be of value in the established disease. The 
patients given steroids in this series were few and did not gain any additional benefit.

The difference between Elkington's findings $(1936,1951)$ and ours concerning progression of the clinical state to paraplegia may well reflect the alteration in predominance of involvement of the various sites in the spinal cord. Major vascular supply to the cord from one of the lower lumbar vessels is unusual, and hence arachnoiditis at this site manifests itself as a multiple root problem, whereas if the cervical or thoracic regions are involved intramedullary cavitation may occur (Mackay, 1939; Lubin, 1940) due either to vascular deprivation or compression of the spinal cord from which paraplegia results. It is, therefore, of interest that none of our cases progressing to paraplegia had arachnoiditis restricted to the lumbar region. Indeed, in five of the seven patients, the third to sixth thoracic segments, which represents the vascular watershed, were involved. In the remaining two patients the involvement was of the tenth and eleventh thoracic segments and this suggests that the artery of Adamkiewicz in these patients entered the spinal column at or above this level. It is difficult to explain why arachnoiditis which was distal to the sixth thoracic segment should result in a quadriparesis in one patient, but the three patients who had spastic paraparesis had involvement of the thoracolumbar junction. In the remaining cases the condition was restricted to the lumbar region.

\section{Conclusion}

The patterns of production of spinal arachnoiditis and hence the sites involved and the degree of neurological progression have changed. Usually several factors are involved, and rarely does contrast medium alone produce spinal arachnoiditis. It is essential that procedures on the spine such as lumbar punctures should be undertaken if possible by experienced personnel. Furthermore, if there are technical difficulties, or if the patient has had a previous spinal illness, contrast media or other agents should not be inserted into the spinal theca if at all avoidable.

The most commonly associated previous spinal condition is now intervertebral disc disease, and this accounts for the change in outcome in the majority of cases who continue to have radicular manifestations, in particular pain, and rarely, if ever, progress to paraplegia unless the thoracic or cervical regions are involved.

The outcome is not related to the presence of a myelographic block or a high cerebrospinal fluid protein content. Direct surgery does not appear to have any clear-cut role in the management of this chronic condition.

We would like to acknowledge the kindness of the consultant staff of the Institute of Neurological Sciences, Glasgow, for allowing us access to their case material, and to thank Miss H. Wilson, Mrs W. McDermid, and Mrs J. Rubython for typing the manuscript.

\section{References}

Ahlgren, P. (1973). Long term side effects after myelography with water soluble contrast media: Conturex Conray meglumine 282 and Dimer-X. Neuroradiology. 6, 206-211.

Alpers, B. J., and Forster, F. M. (1945). The reparative process in subarachnoid hemorrhage. Journal of Neuropathology and Experimental Pathology, 4, 262-268.

Austin, G. (1972). The Spinal Cord. Basic Aspects and Surgical Considerations. Second edition. Charles C. Thomas: Springfield, Illinois.

Autio, E., Suolanen, J., Norrbäck, S., and Slätis, P. (1972). Adhesive arachnoiditis after lumbar myelography with meglumine iothalamate. Acta Radiologica Diagnosis, 12, 17-24.

Bagley, C. (1928a). Blood in the cerebrospinal fluid: resultant functional and organic alterations in the central nervous system. A. Experimental data. Archives of Surgery, 17, 18-38.

Bagley, C. (1928b). Blood in the cerebrospinal fluid: resultant functional and organic alterations in the central nervous system. B. Clinical data. Archives of Surgery, 17, 39-81.

Barker, L. F., and Ford, F. R. (1937). Chronic arachnoiditis obliterating the spinal subarachnoid space. Journal of the American Medical Association, 109, 785-787.

Bergeron, R. T., Rumbaugh, C. L., Fang, H. and Cravioto, H. (1971). Experimental pantopaque arachnoidlitis in the monkey. Radiology, 99, 95101.

Bernat, J. L. (1977). Iophendylate myelography in multiple sclerosis. Lancet, 1, 48-49.

Bernat, J. L., Sadowsky, C. H., Vincent, F. M., Nordgren, R. E., and Margolis, G. (1976). Sclerosing spinal pachymeningitis: a complication of intrathecal administration of Depo-Medrol for multiple sclerosis. Journal of Neurology, Neurosurgery, and Psychiatry, 39, 1124-1128.

Brain, W. R., and Walton, J. N. (1969). Brain's Diseases of the Nervous System. Seventh edition. Oxford University Press: London.

Christensen. E. (1942). Chronic adhesive spinal arachnoiditis. Acta Psychiatrica Scandinavica, 17, 23-38.

Davidoff, L. M., Gass, H., and Grossman, J. (1947). Post operative spinal adhesive arachnoiditis and recurrent spinal tumors. Journal of Neurosurgery, 4, 451-464. 
Duke, R. J., and Hashimoto, S. A. (1974). Familial spinal arachnoiditis. A new entity. Archives of Neurology (Chicago), 30, 300-303.

Elkington, J. St. C. (1936). Meningitis serosa circumscripta spinalis (spinal arachnoiditis). Brain, 59, 181-203.

Elkington, J. St. C. (1951). Arachnoiditis. In Modern Trends in Neurology. 5. Edited by A. Fielding. Butterworth: London.

Elsberg, C. A. (1942). Surgical Diseases of the Spinal Cord Membranes and Nerve Roots: Symptoms, Diagnosis and Treatment. Lewis: London.

Erickson, T. C., Masten, M. G., and Suckle, H. M. (1946). Complications of intrathecal use of penicillin. Journal of the American Medical Association, 132, 561-565.

Feder, B. H., and Smith, J. L. (1962). Roentgen therapy in chronic spinal arachnoiditis. Radiology, 78, 192-197.

French, J. D. (1946). Clinical manifestations of lumbar spinal arachnoiditis: a report of thirteen cases. Surgery, 20, 718-729.

Halaburt, H., and Lester, J. (1973). Leptomeningeal changes following lumbar myelography with water soluble contrast media (meglumine iothalamate and methiodal sodium). Neuroradiology, 5, 70-76.

Hammes, E. M. (1944). Reaction of the meninges to blood. Archives of Neurology and Psychiatry (Chicago), 52, 505-514.

Horsley, V. (1909). Chronic spinal meningitis: its differential diagnosis and surgical treatment. British Medical Journal, 1, 513-517.

Howland, W. J., and Curry, J. L. (1966). Pantopaque arachnoiditis: experimental study of blood as a potentiating agent and cortico steroids as an ameliorating agent. Acta Radiologica Diagnosis, 5, 1032-1041.

Irstam, L., and Rosencrantz, M. (1973). Water soluble contrast media and adhesive arachnoiditis: 1, reinvestigation of non operated cases. Acta Radiologica Diagnosis, 14, 497-506.

Irstam, L. and Rosencrantz, M. (1974). Water soluble contrast media and adhesive arachnoiditis: 2, reinvestigation of operated cases. Acta Radiologica Diagnosis, 15, 1-15.

Irstam, L., Sundström, R., and Sigstedt, B. (1974). Lumbar myelography and adhesive arachnoiditis. Acta Radiologica Diagnosis, 15, 356-368.

Jacobsen, H. H., and Lester, J. (1969). Diagnosis of spinal arachnoiditis by air myelography. Acta Neurologica Scandinavica, 45, 376-379.

Jennett, B., and Shaw, M. D. M. (1976). The natural history of lumbar disc disease. Presented at the combined meeting of Nederlandse Vereniging Van Neurochirurgen and the Society of British Neurological Surgeons, Amsterdam, Netherlands.

Kaufmann, P., and Jeans, W. D. (1976). Reactions to iphendylate in relation to multiple sclerosis: Lancet, 2, 1000-1001.

Kennedy, F., Effron, A. S., and Perry, G. (1950). The grave spinal cord paralyses caused by spinal anaesthesia. Surgery, Gynaecology and Obstetrics, 91, 385-398.

Kennedy, F., Somberg, H. M., and Goldberg, B. B. (1945). Arachnoiditis and paralysis following spinal anaesthesia. Journal of the American Medical Association, 129, 664-667.

Kulowski, J., and Scott, W. (1934). Localised adhesive spinal arachnoiditis: an obscure cause of radiating low back pain. Journal of Bone and Joint Surgery, 16, 699-703.

Liliequist, B., and Lundström, B. (1974). Lumbar myelography and arachnoiditis. Neuroradiology, 7, 91-94.

Lombardi, G., and Passerini, A. (1964). Spinal Cord Diseases: a radiological and myelographic analysis. Williams and Wilkins: Baltimore.

Lombardi, G., Passerini, A., and Migliavacca, F. (1962). Spinal arachnoiditis. British Journal of Radiology, 35, 314-320.

Lubin, A. J. (1940). Adhesive spinal arachnoiditis as a cause of intramedullary cavitation: Comparison with syringomyelia. Archives of Neurology and Psychiatry (Chicago), 44, 409-420.

Mackay, R. P. (1939). Chronic adhesive spinal arachnoiditis: a clinical and pathological study. Journal of the American Medical Association, 112, 802-808.

Malmros, R. (1976). Spinal arachnoiditis after myelography with water soluble contrast media. Presented at the combined Meeting of Nederlandse Vereniging Van Neurochirurgen and the Society of British Neurological Surgeons, Amsterdam, Netherlands.

Mendel, K., and Adler, S. (1908). Cited by Elkington (1936).

Meyer, A. (1963). Intoxications. In Greenfield's Neuropathology. Edited by W. Blackwood, W. H. McMenemy, A. Meyer, R. M. Norman, and D. S. Russell. Second edition. Edward Arnold: London.

Millikan, C. H., and Sahs, A. L. (1947). Adhesive arachnoiditis following the intrathecal administration of penicillin. Journal of Iowa State Medical Society, 37, 198-201.

Peacher, W. G., and Robertson, R. C. L. (1945). Pantopaque myelography: results, comparisons of contrast media and spinal fluid reaction. Journal of Neurosurgery, 2, 220-231.

Radberg, C., and Wennberg, E. (1973). Late sequelae following lumbar myelography with water soluble contrast media. Acta Radiologica Diagnosis, 14, 507-512.

Ransforcl, A. C., and Harries, B. J. (1972). Localised arachnoiditis complicating lumbar disc lesions. Journal of Bone and Joint Surgery, 54, 656-665.

Rocovich, P. M. (1947). Adhesive spinal arachnoiditis: a short review. Bulletin of Los Angeles Neurological Society, 12, 69-77.

Rosenbleum, H. E., Long, F. B., Hinchley, T. R., and Trufant, S. A. (1952). Paralysis with saddle block anesthesia in obstetrics. Archives of Neurology and Psychiatry (Chicago), 68, 783-790.

Schwarz, E. (1897). Präparate von einem falle syphilitischer myelomeningitis mit höhlenbildung 
im rüchenmarke und besonderen degenerativ en veränderungen der neurologia. Wiener Klinische Wochenschrift, 10, 177-179.

Seaman, W. B., Marder, S. N., and Rosenbaum, H. E. (1953). The myelographic appearance of adhesive spinal arachnoiditis. Journal of Neurosurgery, 10, 145-153.

Slätis, P., Autio, E., Suolanen, J., and Norrbäck, S. (1974). Hyperosmolarity of the cerebrospinal fluid as a cause of adhesive arachnoiditis in lumbar myelography. Acta Radiologica Diagnosis, 15, 619629.

Smolik. E. A., and Nash, F. D. (1951). Lumbar spinal arachnoiditis: a complication of the intervertebral disc operation. Annals of Surgery, 133, 490-495.
Spiller, W. G., Musser, J. H., and Martin, E. (1903). A case of intradural spinal cyst with operation and recovery. University of Pennsylvania Medical Bulletin, 16, 27-31.

Stookey, B. (1927). Adhesive spinal arachnoiditis simulating spinal cord tumor. Archives of Neurology and Psychiatry (Chicago), 17, 151-178.

Weiss, R. M., Sweeney, L., and Dreyfuss, M. (1962). Circumscribed adhesive spinal arachnoiditis. Journal of Neurosurgery, 19, 435-438.

Winkelman, N. W., Gotten, N., and Scheibert, D. (1953). Localised adhesive spinal arachnoiditis: a study of twenty-five cases with reference to etiology. Transactions of the American Neurological Association, 78, 15-18. 